\title{
The choice of fetal bovine serum influences the degree of spontaneous mineralization on silk fibroin scaffolds in $3 \mathrm{D}$ cell cultures

\author{
Samantha J Paulsen'1, Jolanda R Vetsch ${ }^{1}$, Ralph Müller' ${ }^{1}$, Sandra Hofmann ${ }^{1}$
} \\ 1 Institute for Biomechanics, ETH Zurich, Zurich, Switzerland
}

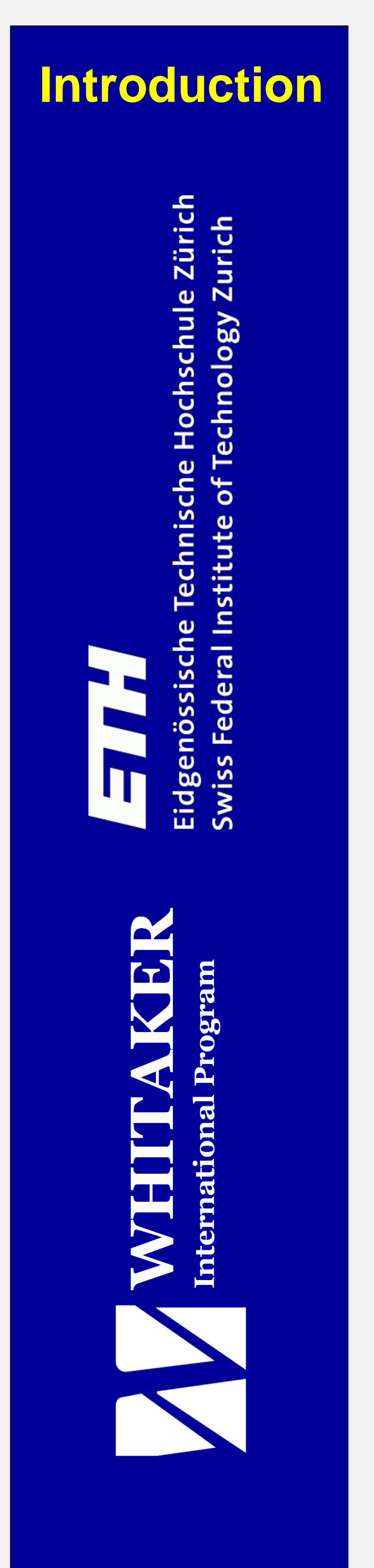

Methods

Results \& Discussion

Conclusions
Silk fibroin (SF) sponges are promising scaffolds for bone tissue engineering due to their biocompatibility, desirable mechanical properties, and their ability to support calciumphosphate formation in vitro ${ }^{1}$.

However, spontaneous mineralization can occur in acellular SF scaffolds that is indistinguishable from cell-mediated mineralization. This phenomenon interferes with negative controls and limits our understanding of cells' role in scaffold mineralization.

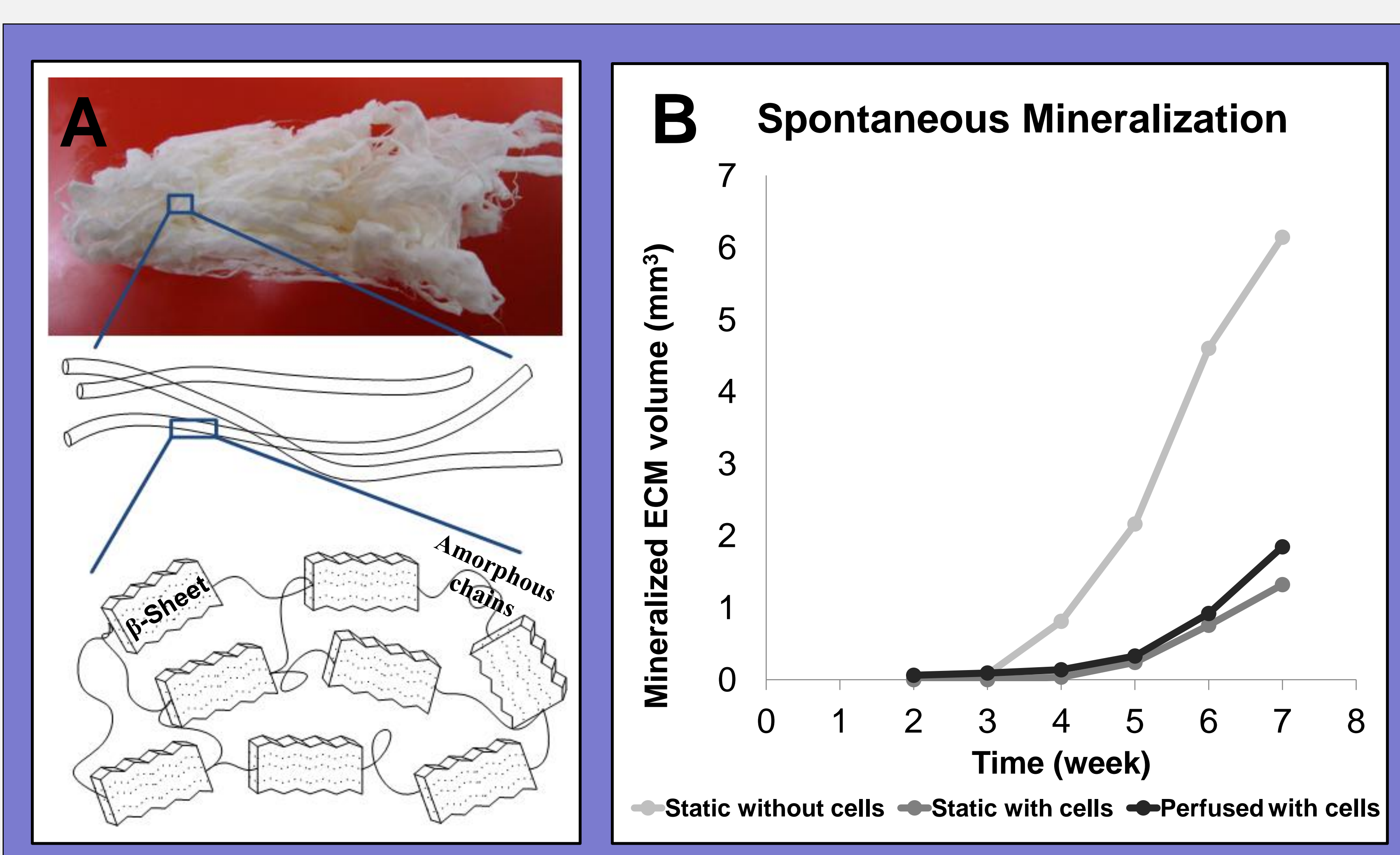

Figure 1: SF structure and spontaneous mineralization

(A) Amorphous, hydrophilic chains in SF can act as nucleation sites for hydroxyapatite crystals². (B) In some previous studies acellular SF scaffolds have had higher levels of mineralization than cellularized scaffolds.

To discover the effects of fetal bovine serum (FBS) on spontaneous mineralization rates, we used four types of commercially available FBS in osteogenic and control medium then cultured scaffolds either with or without cells for 7 weeks.

To analyze the level of mineralization, we performed:

- Calcium assay $(\mathrm{N}=3)$ at weeks 3,5 , and 7

- $\mu \mathrm{CT}$ analysis $(\mathrm{N}=2)$ at week 7

- H\&E and Von Kossa Staining $(\mathrm{N}=2)$ at week 7

\begin{tabular}{|c|c|c|}
\hline $\begin{array}{c}\text { Control no } \\
\text { Cells }\end{array}$ & $\begin{array}{c}\text { Osteogenic } \\
\text { no Cells }\end{array}$ & Selected FBS Varieties \\
$\begin{array}{c}\text { Control } \\
\text { Cells }\end{array}$ & $\begin{array}{c}\text { Osteogenic } \\
\text { Cells }\end{array}$ & $\begin{array}{c}\text { FBS Standard Quality (PAA) } \\
\text { FBS Superior (Biochrom) }\end{array}$ \\
\hline
\end{tabular}

Figure 2: Experimental groups and FBS

(Left) List of experimental groups. (Right) List of FBS varieties used, with the manufacturer listed in parentheses.

Though we expected calcium content to remain low in acellular scaffolds, by week 7 the calcium content in some acellular scaffolds was nearly half the amount of their cellularized counterparts. Calcium content varied significantly between FBS brands in acellular scaffolds, but not in cellularized scaffolds, and $\mu C T$ analysis showed similar trends. PAA Gold and PAA Standard Quality both displayed relatively low levels of mineralization when compared to Biochrom's FBS Superior or FBS Standard from Gibco.

These results show that variations in FBS have a significant effect on spontaneous mineralization rates in acellular SF scaffolds. We need to learn more about the process of mineralization and how variations in media composition affect tissue calcification in 3D cell culture.

The authors state that there is no conflict of interests.

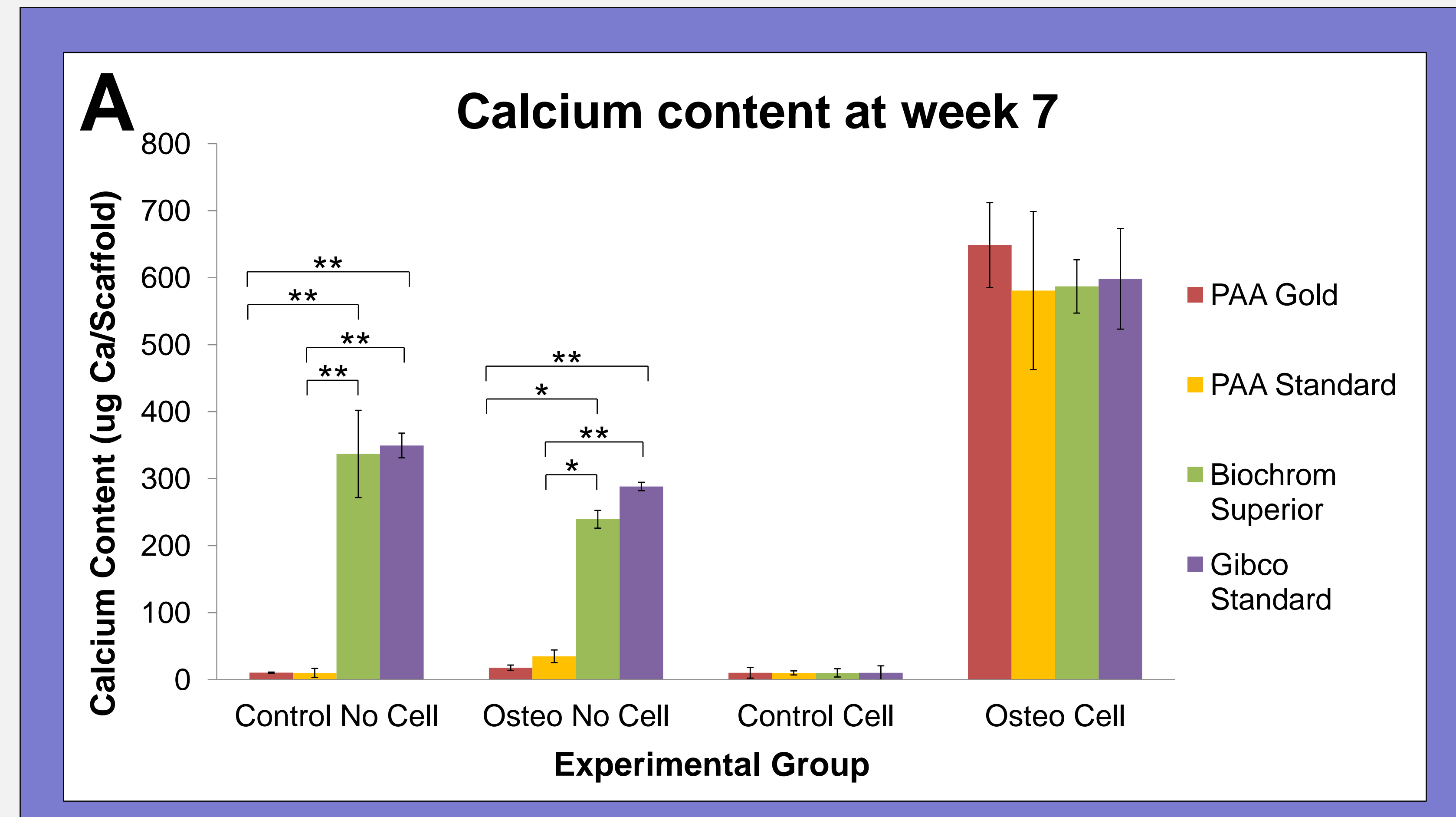

Figure 3: Calcium Assay

At week 7 there are significant $\left({ }^{*} \alpha<0.05,{ }^{* *} \alpha<0.01\right)$ differences in calcium content within no cell groups, but no significant differences within either cell group (osteogenic or control).
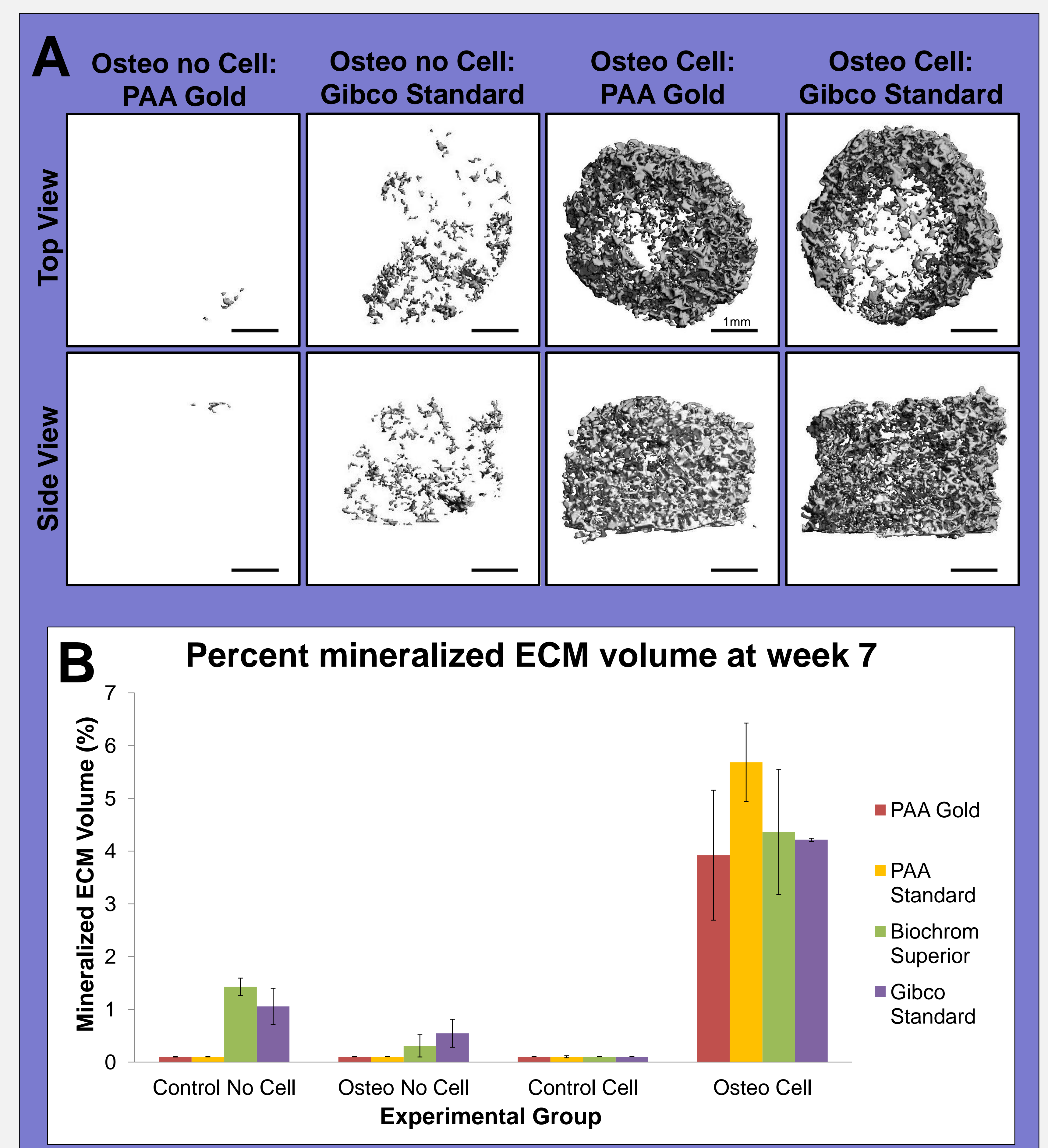

Figure 4: $\mu C T$ data for dried scaffolds at week 7. (A) Top and side view for $3 \mathrm{D}$ reconstructions of $\mu \mathrm{CT}$ scans. PAA Gold was selected to represent the low spontaneous mineralization group, while FBS from Gibco is representative of the high spontaneous mineralization group. (B) Plot for average percent bone volume to total volume for scaffolds.

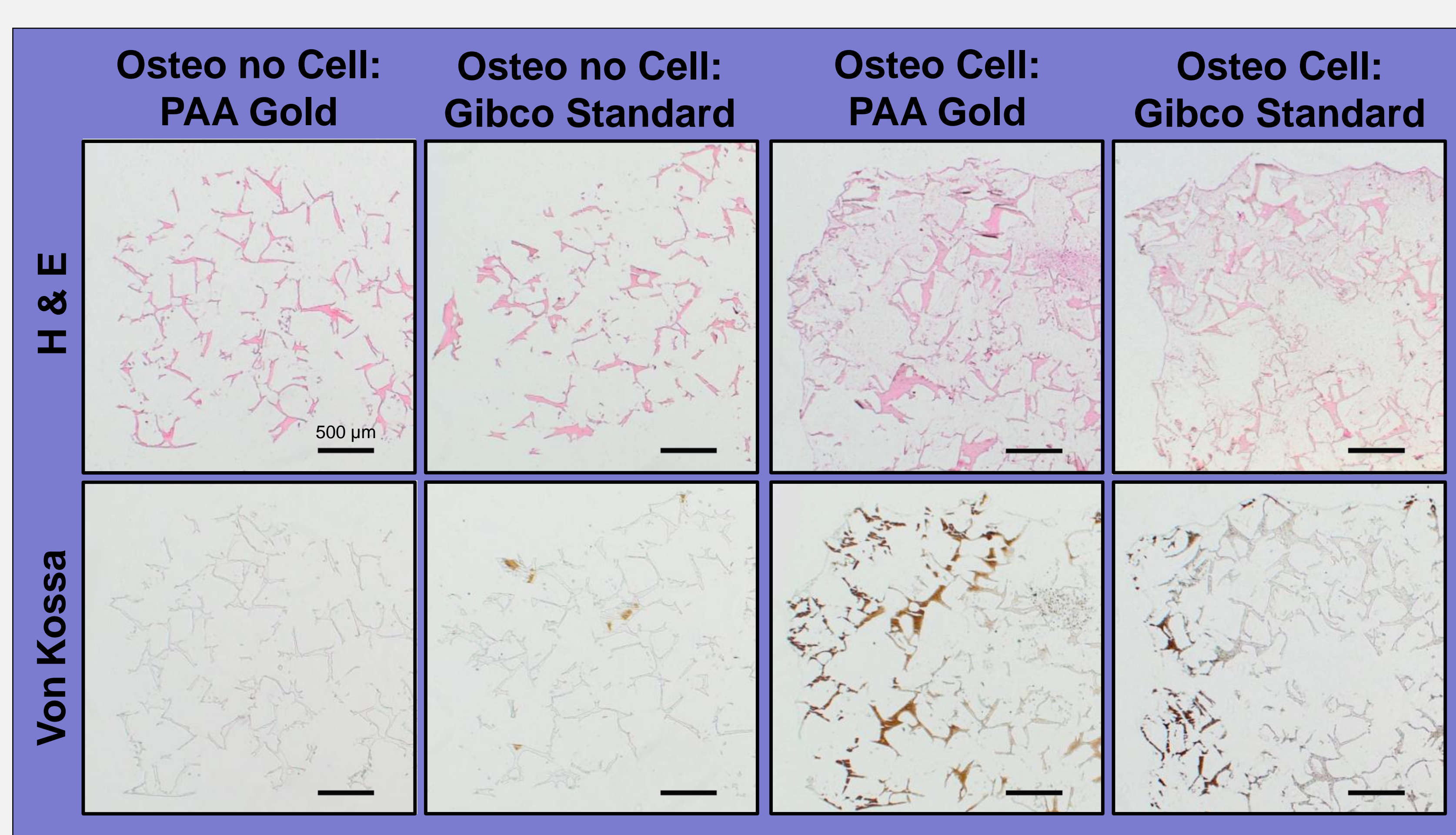

Figure 5: H\&E and Von Kossa staining for histological samples at week 7. Both osteogenic, cellularized scaffolds show high levels of staining, while only the acellular scaffold cultured with Gibco's FBS shows staining in Von Kossa.

[1] Kearns, V., et al. (2008). [2] Marelli, B. et al. (2011).

The authors gratefully acknowledge funding from the European Union (BIODESIGN FP7-NMP-2012-262948) and the Whitaker International Program. 